\title{
ORAL HEALTH STATUS AND ORAL HEALTH RELATED QUALITY OF LIFE IN ADOLESCENT WORKERS
}

\author{
SULTAN KELES ${ }^{1}$, FILIZ ABACIGIL ${ }^{2}$, FILIZ ADANA ${ }^{3}$
}

\author{
${ }^{1}$ Department of Pediatric Dentistry, Adnan Menderes University, Aydin, Turkey \\ ${ }^{2}$ Department of Public Health, Adnan Menderes University, Aydin, Turkey \\ ${ }^{3}$ Department of Public Health Nursing, Adnan Menderes University, Aydin, Turkey
}

\begin{abstract}
Background and aim. Oral health status and oral health related quality of life (OHRQoL) of working adolescents has been very little reported in literature. Therefore, this study aimed to determine oral health status and OHRQoL in a group of adolescent workers.

Methods. This cross-sectional study was conducted in an apprentice training center in western Turkey between December 2016 and January 2017. The study group population was 585, and the sample size was 514 students between 14 and 18 years old. The Decayed, Missing, and Filled Teeth (DMFT) Index, the Turkish version of the Oral Health Impact Profile-14 (OHIP-14), and a form requesting the socio-demographic information of the students were used as data collection tools. Permissions were obtained from the relevant school, parents, students, and ethical committee. The data were analyzed using descriptive statistics, the Student's t-test, and the Pearson correlation coefficient.

Results. The results showed significant relationships between the tooth brushing frequency, dental visit frequency, dental trauma history, smoking, and the OHIP-14 subdomains $(p<0.05)$.

Conclusion. Poor oral health and a lack of good oral health attitudes may have negative impact on the oral health related quality of life (OHRQoL) of working adolescents. Dental health education programs in collaboration with schools and dental health services may be beneficial for promoting oral health and improving the OHRQoL of working adolescents.
\end{abstract}

Keywords: oral health, quality of life, adolescent

\section{Background and aim}

Child labor remains a major problem in developing countries, in which 250 million children aged 4-15 years old are reported to be working. In Turkey, child labor has been increasing, giving rise to psychological, physical, and social problems in working children. According to the International Labor Organization (ILO), the minimum working age for children is 15 years old. However, in Turkey, the minimum working age is 14 years old. According to the last recorded data from the Child Labor Force Survey conducted in 2012 by the Turkish Statistical

Manuscript received: 19.12.2017

Received in revised form: 08.06.2018

Accepted: 24.06.2018

Address for correspondence: dtsultank@gmail.com
Institute, $893,000(5.9 \%)$ children between the ages of 6 and 17 years old were confirmed to be working [1].

There have been many studies about the protection of working children in Turkey, as well as strategies to ensure they continue their education [2-4]. In 1992, Turkey joined the ILO's International Program on the Elimination of Child Labor, and consequently, there are now more than 300 centers providing 3-year vocational training for adolescents aged 14-19 years old who have completed primary education. These centers provide theoretical vocational education one day per week, and the adolescents work in their assigned work placements on the remaining days [2].

Few studies have described the general health status of Turkish child workers [2,3,5]. Caglayan et al. [2] 
assessed the general health status of children studying at a vocational education center, and showed that the physical and mental health of children who work long hours from an early age are negatively affected. Esin et al. [3] analyzed the health problems and occupational risks associated with working children, and they found that the working environments had negative effects on the children's health. Ornek and Esin [5] stated that work and working conditions have strong influences on psychological health, and that these factors have an higher negative impact on children's health, when compared to adults, because of their developmental stage.

Oral/dental health is a component of the overall health. Poor oral health may affect the general health by causing considerable pain and suffering, diet alterations, and poor speech, quality of life, and general well-being. Oral diseases are the most common chronic diseases, with substantial public health implications due to their prevalence, impacts on both individuals and society, and associated treatment costs [6,7].

The oral health related quality of life (OHRQoL) reflects the individuals' perception about their oral health and the impacts of oral diseases may have on their daily functioning, social interactions, well-being, and psychological status $[7,8]$.

The Oral Health Impact Profile-14 (OHIP-14) is a scale commonly used to determine an individual's perceptions of the social impacts of oral disorders on their well-being. It also provides an indication of the level of discomfort, disability, and/or dysfunction they feel as a result of their oral conditions [8].

No previous studies have assessed the oral/dental health status and the related factors on the OHRQoL of working adolescents in Turkey. Therefore, this study aimed to evaluate the oral/dental health status and oral health attidues on the OHRQoL of children attending a vocational training center in western Turkey.

\section{Materials and methods}

This cross-sectional study was carried out between December 2016 and January 2017 at a vocational training center in Aydin, Turkey. No selection criteria or sampling methods were specified for the study; the objective was to include all students aged $14-18$ years old $(n=585)$. Of the 585 students, 71 were excluded because they were not on the school premises on the days the study was conducted. Thus, 514 students $(87.9 \%)$ were included in this research. Written informed consent was taken from all the students and their parents/caregivers prior to their participation in the study. The study had two main parts, including a dental examination and a questionnaire.

\section{Questionnaire}

In the first part of the questionnaire, the participants were asked about their age, gender, family income level, and their parents' education. The participants were also asked about their oral health related habits and attitudes, like smoking, dental visit frequency, and tooth brushing. The dental visit and tooth brushing frequencies were dichotomized as "never" and "other," and those who never visited the dentist and never brushed their teeth were categorized as "never."

In the second part of the questionnaire, the OHRQoL of the participants was evaluated using the Turkish version of the OHIP-14 scale. The OHIP-14 is comprised of 14 questions grouped under 7 domains, including functional limitation, physical pain, psychological discomfort, physical disability, psychological disability, social disability, and handicap [9]. The index items were rated as follows: $0=$ never, $1=$ rarely, $2=$ sometimes, $3=$ often, and $4=$ always. The scores are summed to provide a total score (range $=0$ to 56), in which a score of 0 indicated that the OHRQoL was very good, while a score of 56 indicated that the OHRQoL was very poor. The mean domain scores were calculated by dividing the sum of the subdomain score by the number of questions in that subdomain. Each of the OHIP-14 responses was assigned a score of 0 if the response was "never" or "hardly ever" and a score of 1 if the response was "occasionally," "fairly often," or "very often", dichotomizing responses into "Absence of impact" versus "Presence of impact".

The Turkish validation of the OHIP-14 was performed by Mumcu et al., and a Cronbach's alpha value of 0.94 was obtained [10]. The questionnaires were selfcompleted by the students under supervision, and the evaluation lasted 20 minutes.

\section{Oral Health Examination}

The intraoral examinations were performed under standardized conditions by the same dental specialist using disposable mirrors and periodontal probes (WHO-621 Trinity; São Paulo, SP, Brazil) on the base of the World Health Organization (WHO) oral health examination criteria [11]. The Decayed, Missing, and Filled Teeth (DMFT) Index was used to evaluate the participants' oral health. In addition, the dental examinations included an evaluation of the periodontal status, presence of malocclusion, and dental trauma.

The clinical periodontal status was assessed by the same examiner, based on the Community Periodontal Index (CPI) [12], and malocclusion was categorized based on the Dental Aesthetic Index (DAI) $[12,13]$. The presence of dental trauma was recorded via the Andreasen classification system [14]. The periodontal health was evaluated in the clinical examination, followed by an evaluation of the presence of dental trauma, decay, and malocclusion. The clinical variables were divided into the following: malocclusion presence (DAI $>25$ ) or absence $($ DAI $\leq 25)$, periodontal status healthy $($ CPI $<1)$ or 
unhealthy (CPI $\geq 1$ ), and dental trauma presence (restored fracture, enamel fracture only, fracture involving dentin and/or pulp) or absence (no clinical signs of dental trauma). The examination of each student took approximately 20 minutes, and the dental specialist recorded the data during the examination. The oral examination and recording data took approximately 20-30 minutes per individual.

\section{Statistical Analysis}

All the statistical analyses were conducted using the Statistical Package for the Social Sciences version 18.0 (SPSS Inc., Chicago, IL, USA). The descriptive statistics were presented as percentages and means \pm standard deviations. The Student's t-test was used to compare the continuous parametric variables of the independent groups. A 5\% type 1 error level was used to infer statistical significance.

\section{Ethical Considerations}

Permissions were obtained from the relevant school, students, parents, and ethical committee (ref. no. 2016/1023). This study did not have any financial support.

\section{Results}

The mean age of the students included in the study was $16.6 \pm 1.3$ years old; $90.5 \%$ were males and $9.5 \%$ were females. More than one-half of the students' mothers $(62.2 \%)$ and fathers $(54.1 \%)$ had attended primary school or less. The income level of $25.3 \%$ of the students was less than the expense level, that of $63.1 \%$ was equal to the expense level, and that of $11.6 \%$ was more than the expense level. Less than one-half $(41.6 \%)$ of the students were smokers.

As many as $43.4 \%$ of the participants reported that they had never been to the dentist, 34\% visited the dentist only when there was a problem, $27.8 \%$ visited the dentist at least once a year, and $2.5 \%$ visited the dentist less frequently than once a year. The smallest proportion of students $(11.5 \%)$ reported that they never brushed their teeth, while $50.0 \%$ stated that they sometimes brushed their teeth, and $38.5 \%$ stated that they brushed their teeth at least once a day.

The mean DMFT values of the students' were 2.37 \pm 2.45 (minimum $=0$, maximum $=13)$. The mean numbers of decayed, filled, and extracted teeth were $3.07 \pm 1.9$ $($ minimum $=1$, maximum $=12), 2.03 \pm 1.60($ minimum $=1$, maximum $=7)$, and $1.24 \pm 0.5($ minimum $=1$, maximum $=$ 3 ), respectively. The oral/dental health status of the students is presented in Table I.

Out of 437 students, 211 (48.3\%) reported that their oral/dental status had several impacts on their quality of life. The participants' overall OHIP-14 score was 25.83 $\pm 7.36($ minimum $=14$, maximum $=47)$. The OHIP14 subdomain scores were as follows: $1.21 \pm 1.37$ for functional limitations, $1.31 \pm 1.63$ for physical pain, $3.12 \pm$ 2.28 for psychological discomfort, $2.26 \pm 1.95$ for physical disability, $2.5 \pm 2.14$ for psychological disability, $1.74 \pm$ 1.83 for social disability, and $1.43 \pm 1.70$ for handicap.

Table II presents the percentage distributions of each item showing the impacts of the OHIP-14 subdomains on the OHRQoL. Overall, the psychological discomfort subdomain ("Have you been self-conscious about your teeth, mouth, or dentures?") had the highest impact on OHRQoL (49.9\%).

Significant relationships were found between the following: 1) the frequency of tooth brushing and the psychological discomfort subdomain, 2) the dental visit frequency and the physical pain, physical disability, and handicap subdomains, 3) dental trauma and the psychological discomfort, physical disability, psychological disability, and handicap subdomains, and 4) smoking and the psychological discomfort and psychological disability subdomains $(\mathrm{p}<0.05$, Table III).

Table I. Oral health status of working children.

\begin{tabular}{|c|c|c|}
\hline & $\mathbf{N}$ & $\%$ \\
\hline \multicolumn{3}{|l|}{ DMFT } \\
\hline$=0$ & 157 & 30.5 \\
\hline$>0$ & 357 & 69.5 \\
\hline \multicolumn{3}{|l|}{ Decayed teeth } \\
\hline$=0$ & 173 & 33.7 \\
\hline$>0$ & 341 & 66.3 \\
\hline \multicolumn{3}{|l|}{ Missing teeth } \\
\hline$=0$ & 481 & 93.6 \\
\hline$>0$ & 33 & 6.4 \\
\hline \multicolumn{3}{|l|}{ Filled teeth } \\
\hline$=0$ & 450 & 87.5 \\
\hline$>0$ & 64 & 12.5 \\
\hline \multicolumn{3}{|l|}{ Malocclusion } \\
\hline minor or none & 402 & 78.2 \\
\hline definite & 64 & 12.5 \\
\hline severe & 28 & 5.4 \\
\hline handicapping & 20 & 3.9 \\
\hline \multicolumn{3}{|l|}{ Periodontal status } \\
\hline healthy & 2 & 0.4 \\
\hline bleeding & 111 & 23 \\
\hline calculus & 367 & 76.1 \\
\hline pockets $\geq 4 \mathrm{~mm}$ & 2 & 0.4 \\
\hline \multicolumn{3}{|l|}{ Dental trauma } \\
\hline present & 39 & 7.6 \\
\hline absent & 475 & 92.4 \\
\hline
\end{tabular}


Table II. OHIP-14 Oral Health Impact Profile of participants.

\begin{tabular}{|l|l|l|l|l|l|}
\hline \multirow{2}{*}{ Subdomains of OHIP-14 } & \multicolumn{2}{l}{ Absence of impact } & \multicolumn{2}{l|}{ Presence of impact } \\
\cline { 3 - 6 } & & $\%$ & $\mathrm{~N}$ & $\%$ & \\
\hline \multirow{3}{*}{ Functional limitation } & Difficulty to speak & 367 & 75.4 & 120 & 24.6 \\
\cline { 2 - 6 } & Taste of food & 421 & 86.4 & 66 & 13.6 \\
\hline \multirow{3}{*}{ Physical pain } & Pain & 334 & 69 & 150 & 31 \\
\cline { 2 - 6 } & Discomfort when eating & 419 & 85.9 & 69 & 14.1 \\
\hline Psychological discomfort & Worried & 239 & 50.1 & 238 & 49.9 \\
\cline { 2 - 6 } & Tense & 246 & 50.7 & 239 & 49.3 \\
\hline \multirow{3}{*}{ Physical disability } & Unsatisfactory diet & 262 & 54.6 & 218 & 45.4 \\
\cline { 2 - 6 } & Interrupted meals & 341 & 70 & 146 & 30 \\
\hline \multirow{3}{*}{ Psychological disability } & Difficulty to relax & 307 & 63.6 & 176 & 36.4 \\
\cline { 2 - 6 } & Embarrassed & 257 & 53.1 & 227 & 46.9 \\
\hline \multirow{3}{*}{ Social disability } & Stressed with people & 314 & 65.1 & 168 & 34.9 \\
\cline { 2 - 6 } & Difficulty in Daily activities & 364 & 76.2 & 114 & 23.8 \\
\hline \multirow{3}{*}{ Handicap } & Unsatisfied with life & 355 & 74 & 125 & 26 \\
\cline { 2 - 6 } & Unable to do Daily tasks & 386 & 79.6 & 99 & 20.4 \\
\hline
\end{tabular}

Table III. Mean scores on OHIP-14 subdomains according to clinical conditions, oral health behaviors, and smoking habit.

\begin{tabular}{|c|c|c|c|c|c|c|c|c|}
\hline & \begin{tabular}{|l|} 
Functional \\
limitation
\end{tabular} & \begin{tabular}{|l|} 
Physical \\
pain
\end{tabular} & \begin{tabular}{|l|}
$\begin{array}{l}\text { Psychological } \\
\text { discomfort }\end{array}$ \\
\end{tabular} & \begin{tabular}{|l|} 
Physical \\
disability
\end{tabular} & \begin{tabular}{|l|}
$\begin{array}{l}\text { Psychological } \\
\text { disability }\end{array}$ \\
\end{tabular} & \begin{tabular}{|l|} 
Social \\
disability
\end{tabular} & Handicap & \begin{tabular}{|l|} 
OHIP-14 \\
Total score \\
\end{tabular} \\
\hline & \begin{tabular}{|l|} 
Mean \pm SD \\
\end{tabular} & Mean \pm SD & Mean \pm SD & Mean \pm SD & Mean \pm SD & Mean \pm SD & Mean \pm SD & Mean \pm SD \\
\hline \multicolumn{9}{|l|}{ Dental trauma } \\
\hline present & $1.05 \pm 1.35$ & $0.94 \pm 1.33$ & $2.24 \pm 2.19$ & $1.60 \pm 1.92$ & $1.80 \pm 1.95$ & $1.30 \pm 1.60$ & $0.77 \pm 1.41$ & $9.06 \pm 8.11$ \\
\hline absent & $1.19 \pm 1.36$ & $1.32 \pm 1.63$ & $3.22 \pm 2.28$ & $2.32 \pm 1.95$ & $2.62 \pm 2.15$ & $1.80 \pm 1.85$ & $1.48 \pm 1.72$ & $14.13 \pm 8.19$ \\
\hline $\mathrm{t}$ & -0.60 & -1.370 & -2.498 & -2.180 & -2.189 & -1.557 & -2.390 & -3.365 \\
\hline $\mathrm{p}$ & 0.549 & 0.171 & 0.013 & 0.013 & 0.029 & 0.120 & 0.017 & 0.001 \\
\hline \multicolumn{9}{|l|}{ Malocclusion } \\
\hline present & $1.28 \pm 1.43$ & $1.39 \pm 1.55$ & $3.31 \pm 2.16$ & $2.10 \pm 1.97$ & $2.58 \pm 2.07$ & $1.75 \pm 1.83$ & $1.56 \pm 1.67$ & $14.30 \pm 8.36$ \\
\hline absent & $1.17 \pm 1.34$ & $1.26 \pm 1.63$ & $3.08 \pm 2.32$ & $2.31 \pm 1.95$ & $2.55 \pm 2.17$ & $1.74 \pm 1.83$ & $1.39 \pm 1.71$ & $13.57 \pm 8.26$ \\
\hline $\mathrm{t}$ & 0.719 & 0.695 & 0.890 & -0.961 & 0.111 & 0.058 & 0.915 & 0.752 \\
\hline $\mathrm{p}$ & 0.473 & 0.488 & 0.374 & 0.337 & 0.912 & 0.954 & 0.361 & 0.453 \\
\hline \multicolumn{9}{|l|}{\begin{tabular}{|l|} 
Visiting dentist \\
\end{tabular}} \\
\hline never & $1.22 \pm 1.39$ & $1.13 \pm 1.57$ & $2.99 \pm 2.22$ & $2.08 \pm 1.80$ & $2.47 \pm 2.17$ & $1.82 \pm 1.99$ & $1.24 \pm 1.63$ & $13.11 \pm 8.02$ \\
\hline other & $1.21 \pm 1.36$ & $1.44 \pm 1.65$ & $3.26 \pm 2.34$ & $2.43 \pm 2.04$ & $2.55 \pm 2.08$ & $1.66 \pm 1.67$ & $1.61 \pm 1.73$ & $14.23 \pm 8.46$ \\
\hline $\mathrm{t}$ & 0.078 & -2.048 & -1.259 & -1.982 & -0.421 & 0.910 & -2.320 & -1.391 \\
\hline $\mathrm{p}$ & 0.938 & 0.041 & 0.209 & 0.048 & 0.674 & 0.364 & 0.021 & 0.165 \\
\hline \multicolumn{9}{|l|}{ Tooth brushing } \\
\hline never & $1.14 \pm 1.17$ & $1.25 \pm 1.70$ & $2.51 \pm 2.39$ & $1.92 \pm 1.78$ & $2.43 \pm 2.34$ & $1.96 \pm 2.13$ & $1.38 \pm 1.62$ & $12.44 \pm 8.73$ \\
\hline other & $1.23 \pm 1.40$ & $1.33 \pm 1.63$ & $3.23 \pm 2.27$ & $2.33 \pm 1.96$ & $2.55 \pm 2.12$ & $1.72 \pm 1.78$ & $1.45 \pm 1.71$ & $14.1 \pm 8.24$ \\
\hline $\mathrm{t}$ & -0.476 & -0.355 & -2.181 & -1.482 & -0.371 & 0.755 & -0.304 & -1.277 \\
\hline $\mathrm{p}$ & 0.634 & 0.723 & 0.030 & 0.139 & 0.711 & 0.453 & 0.761 & 0.202 \\
\hline \multicolumn{9}{|l|}{ Smoking } \\
\hline yes & $1.24 \pm 1.31$ & $1.46 \pm 1.77$ & $3.53 \pm 2.27$ & $2.33 \pm 2.02$ & $2.83 \pm 2.30$ & $1.72 \pm 1.80$ & $1.47 \pm 1.72$ & $14.76 \pm 8.59$ \\
\hline no & $1.19 \pm 1.43$ & $1.17 \pm 1.47$ & $2.74 \pm 2.23$ & $2.19 \pm 1.88$ & $2.20 \pm 1.94$ & $1.75 \pm 1.80$ & $1.39 \pm 1.69$ & $12.76 \pm 7.98$ \\
\hline $\mathrm{t}$ & 0.382 & 1.961 & 3.834 & 0.794 & 3.222 & -0.167 & 0.518 & 2.547 \\
\hline $\mathrm{p}$ & 0.702 & 0.05 & 0.000 & 0.427 & 0.001 & 0.867 & 0.605 & 0.011 \\
\hline
\end{tabular}




\section{Discussion}

In the present study, many clinical parameters, including the dental health status, periodontal health, malocclusion, and dental trauma, were evaluated to assess the oral health status of working adolescents. Moreover, this study evaluated the impact of oral health status and oral health attitudes on OHRQoL of working adolescents. This study revealed that the frequency of visits to a dentist, tooth brushing, presence of traumatic dental injuries, and smoking had impacts on the OHRQoL of adolescent workers.

Although there have been studies that evaluated the overall health status of working children and adolescents, few studies have assessed the oral/dental health and OHRQoL of adolescent workers [2]. Therefore, the results of the present study provide valuable information about a relatively neglected population.

The students' mean DMFT value was $2.37 \pm 2.45$, and $69.5 \%$ of the participants had the DMFT values greater than 0 . However, different DMFT values in similar age groups have been reported in other studies. Gökalp et al. [15] reported a mean DMFT value of 2.3 in adolescents aged 15 years old, Bal et al. [16] reported a mean DMFT value of 4.26 in nursing students, and Namal et al. [17] reported a mean DMFT value of 4.96 in participants aged 18-19 years old. In the present study, we observed that the individuals' mean DMFT values were either equal to or lower than the mean DMFT values of individuals of the same age group reported abovementioned studies.

About $91.6 \%$ of students had poor periodontal health in this study. Gökalp et al. [15] found that $44 \%$ of the adolescents had unhealthy periodontal tissues in their study including participants aged 15 years old. Moreover, Turkish data from the WHO Global Oral Health Program showed that $74 \%$ of $15-19$ year old individuals had unhealthy periodontal tissue. We found that the periodontal health in our sample was poorer than that of the participants included in other studies. This result may be due to both insufficient oral hygiene practices and insufficient regular dentist visits of the study group. Our results may also be affected because working adolescents may not have sufficient time for self-care activities such as oral hygiene.

In the present study, $11.5 \%$ of the students stated that they never brushed their teeth, whereas $43.4 \%$ stated that they had never been to the dentist. Bal et al. [16] found that $88.9 \%$ of nursing students brushed their teeth at least twice a day. In our study, only $38.5 \%$ of the students in the nearly same age group reported brushing their teeth at least once a day. This difference may be because the two groups are in different fields of study; it is likely that nursing students are more aware of health topics and the importance of daily oral/dental healthcare practices.

Individuals who do not attend dental check-ups are more likely to have a poor dental status and worse subjective oral health than people who usually attend dental check-ups [18]. Only $27.8 \%$ of the students participating in this study stated that they regularly attended dental check-ups. Montero et al. [19] reported that regular dental check-ups improve the OHRQoL, and that the individuals who only went to check-ups when there was a problem exhibited increased OHIP-14 scores measuring physical pain. Our findings are consistent with this study; we found significant correlations between frequency of dental visit and the physical pain, physical disability, and handicap subdomains of OHIP-14.

In our study, those who never brushed their teeth stated that their OHRQoL was affected by psychological discomfort (OHIP-14 subdomain), Dahl et al. [20] evaluated the correlation between the tooth brushing frequency and the OHRQoL using the OHIP-14 scale among 3,538 individuals, and they reported that individuals who used toothpicks on a daily basis had better oral hygiene and OHRQoL.

In our study, the malocclusion prevalence, based on the DAI, was $21.8 \%$. Various malocclusion prevalence rates have been noted across studies, possibly due to a genetic predisposition, cross-cultural differences in living standards, growth variations, facial skeleton development, and occlusion [21]. There have been many studies demonstrating that malocclusion can affect the OHRQoL [22-24]. Dalai et al. observed higher frequency of feeling tense, embarrassed, and irritable in patients with high orthodontic treatment need compared to those with mild or borderline malocclusion [23]. Choi et al. stated that severe malocclusion is significantly associated with functional limitation, physical pain, and social disability in young adults [25]. Contrary to these studies, we found no significant effect of malocclusion on the OHRQoL. This may be due to the low malocclusion frequency in the study group, or because the aforementioned studies were performed on patients who had high orthodontic treatment needs.

Lauridsen et al. stated that the anterior teeth are most frequently affected by dental trauma, due to their location [26]. El-Kalla et al. reported that dental trauma has a negative impact on quality of life regarding social, functional, and emotional aspects if left unrestored. [27]. In accordance with their study, we found that teeth broken due to trauma in the anterior region, which were left untreated, affected the OHRQoL of our participants. Soares et al stated that enamel fracture had no significant impact on children' quality of life, while enamel-dentin fracture did have an impact on quality of life [28]. We found that all the teeth exposed to dental trauma had enamel-dentin fracture, and they were left untreated in our study group. This may explain the negative effects of dental trauma on psychological disability, psychological discomfort, and physical disability subdomains in our sample.

Tobacco has been associated with gingival and periodontal inflammatory disorders, tooth staining, 
potentially malignant disorders, and oral cancer [29,30]. Although the effects of smoking on oral health are well documented, there is little information about its effects on the OHRQoL. In the present study, smoking affected the OHRQoL in the psychological discomfort and psychological disability subdomains.

Leite et al., have concluded that smoking has a detrimental effect on the incidence and progression of periodontitis that is a chronic destructive inflammatory condition affecting the supporting structures of the teeth [31]. In our study, although the periodontal health of the participants was poor, its effect on OHRQoL was not statistically significant. Therefore, it is proposed that the effects of smoking on the OHRQoL are manifested more in terms of tooth discoloration and bad breath than in terms of changes in the periodontal tissues. In addition, the young age of the sample group may mean that the duration of cigarette smoke exposure was too short to damage the periodontal health.

Our study indicates that the OHRQoL is poor in working Turkish adolescents. Although previous studies have shown that labor has negative effects on the growth and development of children, data on the oral/dental health of working children is scarce $[2,3,32]$. Thus, the present study reveals important information about the oral/ dental health and OHRQoL of working children. In the present study, the DMFT values did not differ from those obtained from other studies of adolescents of similar age groups; however, the periodontal health was poorer in our participants than in those of participants at a similar age in other studies. Despite the poor oral/dental findings, the only significant association occurred between the presence of dental trauma and the OHRQoL. This may be because fractured teeth can cause a poor aesthetic image, if they leave untreated in this age group. On the other hand, the practices related to the oral/dental health were associated with many of the OHIP-14 subdomains.

\section{Conclusions}

This study has provided evidence that the oral health status and oral health attitudes have impacts on the OHRQoL of working adolescents. The DMFT values of the working adolescents in this study were not different from those observed in non-workers of a similar age group in previous studies. However, to prevent future complications, such as cavities, periodontal problems, and tooth loss due to bad oral hygiene as determined in the study group, an emphasis should be placed on oral/dental health education at an early age. These study findings can be used as a guideline for the prevention of oral/dental health problems in adolescent workers by health professionals and official investigators. Designating areas within the workplace where tooth brushing can be performed, informing students of oral/dental health within the occupational health and safety provisions in schools, and obligatory dentist visits could be beneficial for improving the oral/dental health and OHRQoL of these individuals.

\section{References}

1. Turkish Statistical Institute. Child Labor Survey 2012. (2012). Available from: http://www.turkstat.gov.tr/PreHaberBultenleri. do? $\mathrm{id}=13659$

2. Caglayan C, Hamzaoglu O, Yavuz CI, Yüksel S. Working conditions and health status of child workers: cross-sectional study of the students at an apprenticeship school in Kocaeli. Pediatr Int. 2010;52(1):6-12.

3. Esin MN, Bulduk S, Ince H. Workrelated risks and health problems of working children in urban Istanbul, Turkey. J Occup Health. 2005;47(5):431-436.

4. Bademci HÖ, Karadayı EF, Pur KİG, Kurt Z, Warfa N. Improving psychosocial well-being of child laborers and young people who are engaged in low-income economic activities in Istanbul, Turkey. Child Youth Serv. 2017;38(4):272-284.

5. Ornek OK, Esin MN. Psychological Health Problems Among Adolescent Workers and Associated Factors in Istanbul, Turkey. Saf Health Work. 2018;9(1):101-108.

6 . Sheiham A. Oral health, general health and quality of life. Bull World Health Org. 2005 Sep;83(9):644. .

7. Sischo L, Broder HL. Oral health-related quality of life: what, why, how, and future implications. J Dent Res. 2011;90:12641270 .

8. Locker D, Matear D, Stephens M, Lawrence H, Payne B. Comparison of the GOHAI and OHIP-14 as measures of the oral health-related quality of life of the elderly. Community Dent Oral Epidemiol. 2001;29(5):373-381.

9. Slade GD. Derivation and validation of a short-form oral health impact profile. Community Dent Oral Epidemiol. 1997;25(4):284290.

10. Mumcu G, Inanc N, Ergun T, Ikiz K, Gunes M, Islek U, et al. Oral health related quality of life is affected by disease activity in Behçet's disease. Oral Dis. 2006;12(2):145-151.

11. Oral health surveys: basic methods: World Health Organization; 2013. Available from: http://www.who.int/oral_ health/publications/9789241548649/en/

12. Ainamo J, Barmes D, Beagrie G, Cutress T, Martin J, SardoInfirri J. Development of the World Health Organization (WHO) community periodontal index of treatment needs (CPITN). Int Dent J. 1982;32:281-291.

13. Cons NC, Jenny J, Kohout FJ, Freer TJ, Eismann D. Perceptions of occlusal conditions in Australia, the German Democratic Republic and the United States of America. Int Dent J. 1983;33(2):200-206.

14. Andreasen JO, Andreasen FM, Andersson L. Textbook and color atlas of traumatic injuries to the teeth. John Wiley \& Sons. 2013: 217-230.

15. Gökalp SG, Doğan BG, Tekçiçek MT, Berberoğlu A, Unlüer S. National survey of oral health status of children and adults in Turkey. Community Dent Health. 2010;27(1):12-17.

16. Bal MV, Bengi U, Acıkel C, Saygun I. Oral hygiene and oral health status of the nursing students in Turkey. Gulhane Med J. 2015;57:264-268.

17. Namal N, Can G, Vehid S, Koksal S, Kaypmaz A. Dental health status and risk factors for dental caries in adults in Istanbul, Turkey. East Mediterr Health J. 2008;14(1):110-118.

18. McGrath C, Bedi R. Dental attendance, oral health and the quality of life. Br Dent J. 2001;190(5):262-265. 
19. Montero J, Albaladejo A, Zalba JI. Influence of the usual motivation for dental attendance on dental status and oral health-related quality of life. Med Oral Patol Oral Cir Bucal. 2014;19(3):e225-e231.

20. Dahl KE, Wang NJ, Skau I, Ohrn K. Oral health-related quality of life and associated factors in Norwegian adults. Acta Odontol Scand. 2011;69(4):208-214.

21. Siluvai S, Kshetrimayum N, Reddy CV, Siddanna S, Manjunath M, Rudraswamy S. Malocclusion and related quality of life among 13- to 19-year-old students in Mysore City - a crosssectional study. Oral Health Prev Dent. 2015;13(2):135-141.

22. Chen M, Feng ZC, Liu X, Li ZM, Cai B, Wang DW. Impact of malocclusion on oral health-related quality of life in young adults. Angle Orthod. 2015;85(6):986-991.

23. Abreu LG, Dos Santos TR, Melgaço CA, Abreu MHN, Lages EMB, Paiva SM. Impact of orthodontic treatment on adolescents quality of life: a longitudinal evaluation of treated and untreated individuals. Qual Life Res. 2018 Mar 12. doi: 10.1007/s11136018-1830-7. [Epub ahead of print].

24. Dalaie K, Behnaz M, Khodabakhshi Z, Hosseinpour S. Impact of malocclusion severity on oral health-related quality of life in an Iranian young adult population. Eur J Dent. 2018;12(1), 129-135. 25. Choi SH, Kim BI, Cha JY, Hwang CJ. Impact of malocclusion and common oral diseases on oral health-related quality of life in young adults. Am J Orthod Dentofacial Orthop. 2015;147(5):587-595.

26. Lauridsen E, Hermann NV, Gerds TA, Kreiborg S, Andreasen JO. Pattern of traumatic dental injuries in the permanent dentition among children, adolescents, and adults. Dent Traumatol. 2012;28:358-363.

27. El-Kalla IH, Shalan HM, Bakr RA. Impact of dental trauma on quality of life among 11-14 years schoolchildren. Contemp Clin Dent. 2017;8(4);538-544.

28. Soares JP, Barasuol JC, Torres FM, Giacomin A, Gonçalves $\mathrm{BM}$, Klein $\mathrm{D}$, et al. The impact of crown fracture in the permanent dentition on children's quality of life. Dent Traumatol. 2018;34(3):158-163.

29. Joseph I, Rooban T, Ranganathan K. Tobacco use, oral cancer screening, and oral disease burden in Indian women. Indian $\mathrm{J}$ Dent Res. 2017;28(6):706-710.

30. Fiorini T, Musskopf ML, Oppermann RV, Susin C. Is there a positive effect of smoking cessation on periodontal health? A systematic review. J Periodontol. 2014;85(1):83-91.

31. Leite FRM, Nascimento GG, Scheutz F, López R. Effect of Smoking on Periodontitis: A Systematic Review and Metaregression. Am J Prev Med. 2018;54(6):831-841.

32. Hawamdeh H, Spencer N. Effect of work related variables on growth among working boys in Jordan. J Epidemiol Community Health. 2003;57(2):154-158. 